\title{
AN ETHNOGRAPHIC EXPLANATION OF THE CHANGING LIVELIHOOD OF AGRO-PASTORAL COMMUNITIES IN SINDH, PAKISTAN
}

\author{
Kashif Rustamani \\ University of Florence, Italy \\ Email: Kashif.rustamani@stud.unifi.it
}

\begin{abstract}
The question of the agro-pastoral economy is un-scrutinized within the academic discourse of Pakistan. These communities rely on herding and subsistence agriculture, the former playing a significant role in the socio-economic aspects of life. The late twentieth century marked an era of revolutionized technologies that touched the ground of developing countries, the best-known example is the green revolution. Before the green revolution, most parts of southern Sindh relied on rainwater to cultivate food crops with rudimentary technologies. The modes of production were comprised of livestock and pastoralism. The market-based economic intervention was only gaining roots. Presently, in the region specifically, rains per year have become scarcer, underground water resources such as tube wells are also disappearing. The paper questions that how the climate changes in the locale of study have resulted in a change in economic activities and the social lives of agro-pastoral communities. The present study is an attempt to document, and inform about the social change, to reach a wider level of audience and scientific community. This research is based on empirical evidence. The techniques are more similar to those used in anthropology or ethnology. Data collection and fieldwork are conducted in Southern Sindh known as Wahi Pandhi, which is located in the Dadu district of Sindh. The main economic activity of the area is agriculture and pastoralism. The geography and mode of livelihood in the region are found to be unique in terms of economic, sociopolitical, and cultural aspects. It not only gives us a vantage point to understand the livelihood of the agro-pastorals, but also puts us in a position to form a better policy for these communities. The present study will provide basic policy recommendations to help these communities which are marginalized by their way of subsistence and location in the country.
\end{abstract}

Keywords: Agro-pastoral communities, ethnography, livelihoods, Sindh, Pakistan

\section{INTRODUCTION}

Wahi Pandhi is located in the foothills of the Khirthar mountain range. Kirthar is one of the largest mountain ranges in Pakistan. Geographically, Kirthar Mountains range comes into the Sindh and Balochistan provinces of Pakistan. This mountain forms the boundary between the Sindh (lower Indus plains) to the east and southern Balochistan to the west. The dwellers in the Kirthar range are mainly Baloch, Sindhi, and Brauhvi tribes. Baloch tribes historically migrated toward Sindh for better pastures and grazing land. Hence, approximately three decades ago there was a change, which we call modern technology that started to appear - with this appearance, most Baloch families started to sell a large number of herds (sheep, goats, camel, and cattle) and purchase land for agricultural use and cultivation. Brauhi tribe still resides farther west in the district of Khuzdar, Balochistan (see figure $1)^{1}$. This research is the study of pastoral communities residing around the Kirthar mountain range of Sindhi, Pakistan. Specifically, the study focuses on two main areas of the Kirthar Range, one is Gorakh and the second is Wahi Pandhi ${ }^{2}$. Both locations have a distance of around $40 \mathrm{KM}$. The choice of location involves a detailed study of these two areas and ethnographic research was conducted from August to November 2015. Second-time fieldwork has been conducted from May to August 2018. From 2015 to 2018, researcher had short trips to a locale to understand the environment and social life of the locale.

\footnotetext{
${ }^{1}$ In this figure, researcher has only drawn the area of research locale, otherwise, Khirthar Mountain covers long-range.

${ }^{2}$ Wahi Pandhi lies at the base of Kirthar. It is in district Dadu, Sindh.
} 
The purpose of this study is to show that how the transformations in the region resulted in a change in

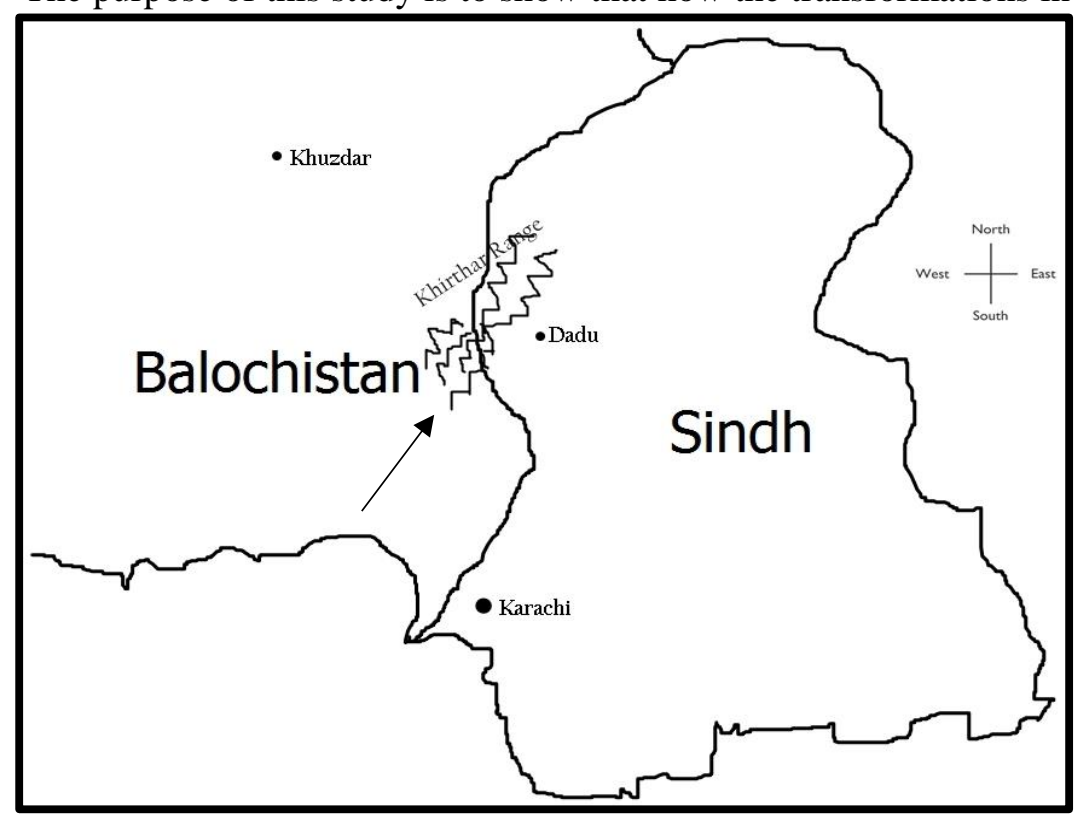

Figure 1: Kirthar Range shown in the map of Sindh economic activities and social lives of agro-pastoral communities. According to one respondent, whose interview I conducted in July 2018, said that "in the year 1980, oil (diesel) engine water machines were purchased by us to maximize the agriculture production. Before that, our land was cultivated solely on rain waters". This shows us, in particular that this region agricultural production was only limited when it rains, or natural water flowed in streams/creeks from Kirthar mountain. The same respondent also added that "we only use to do subsistence agriculture production".

He also mentioned, and it was verified from few other respondents, that the construction of the first-ever road network started in the years 1990 and 1992. When roads were constructed, it also attracted outsiders such as traders ${ }^{3}$ and merchants to reach in the market of the village for purpose of buying and selling. When the outsiders, especially wealthy traders came to market, they influenced local people to grow more agriculture and cultivate large lands. Around the $1980 \mathrm{~s}, 75 \%$ of the population was pastorals and their livelihood depended on livestock and nomadic migration patterns. In an economic survey on Sindh of the years 1843-1933, we find that; Sindh was more pastoral than agricultural. When the British came, Sindh was a pastoral country as Sheeps and goats were in the larger numbers followed by the milch and plough cattle (Choskey \& Sastry, 2015). In 2018, we find that merely $30 \%$ of people entirely relied on livestock and herding. One of the very reasons for this economic shift in livelihood is an expansion of the market into village economies. Godoy, R., et al., noted that the existence of a market transforms the way indigenous people used their renewable natural resources. Intensification of the market in rural areas changes the choices of people in production and pushes them toward surplus production. Even the shortage of land stimulates livelihoods i.e. pastoralism and nomadism to margins and people start to yield accordingly to market demands. Not only extensive market intervention, but population growth is also a reason for the change in pastorals livelihood. According to Abelardo Rodriguez, population growth has increased the already excessively high pressure on the rangeland resources, posing serious questions about the sustainability of the livestock sub-sector in the Kirthar mountains of the Balochistan side (Rodriguez, 1994).

\section{Pastoralism, And Its Pattern of Movement/Migration}

Societies that are dependent on domesticated animals for subsistence and predominantly occupied with herding on natural pasture are characterized as pastoral (Digard, 1990). Although some pastoralists rely on their herds more completely than others do, it is impossible to base subsistence solely on animals. Most pastoralists; therefore, supplement their diet by hunting, gathering, fishing, cultivating, or trading. To get crops, pastoralists either trade with cultivators or do some cultivating or

\footnotetext{
${ }^{3}$ Traders in the local language are known as "Wapari"
} 
gathering themselves. Unlike foraging and cultivation, which existed throughout the world before the Industrial Revolution, pastoralism was confined almost totally to the Old World, particularly in arid zones (Kottak, 2011; Rosman, Rubel, \& Weisgrau, 2009).

Most pastoralists are characterized by similar patterns of husbandry, division of labor, rights in pastures and animals, forms of political organization, and cultural character. Yet they often share forms of social organization, religion, language, and culture with settled communities to whom they are tied through descent, marriage, trade, and exchange (Barth, 1961; Barnard \& Spencer, 2010).

As above literature defines pastoralism related to old World, but it exists in large numbers around the world. The nomadic pastorals are found in the area of Kirthar. The ethnic composition of the area is consisting of mostly Baloch dissent castes and tribes. Some of true nomadic subtribes are; Malokhani, Khohira, Jarwani, and Bozdar in Wahi Pandhi and in Gorakh area are Halkhani, Bijarani, Brohi, Mirwari and Rind.

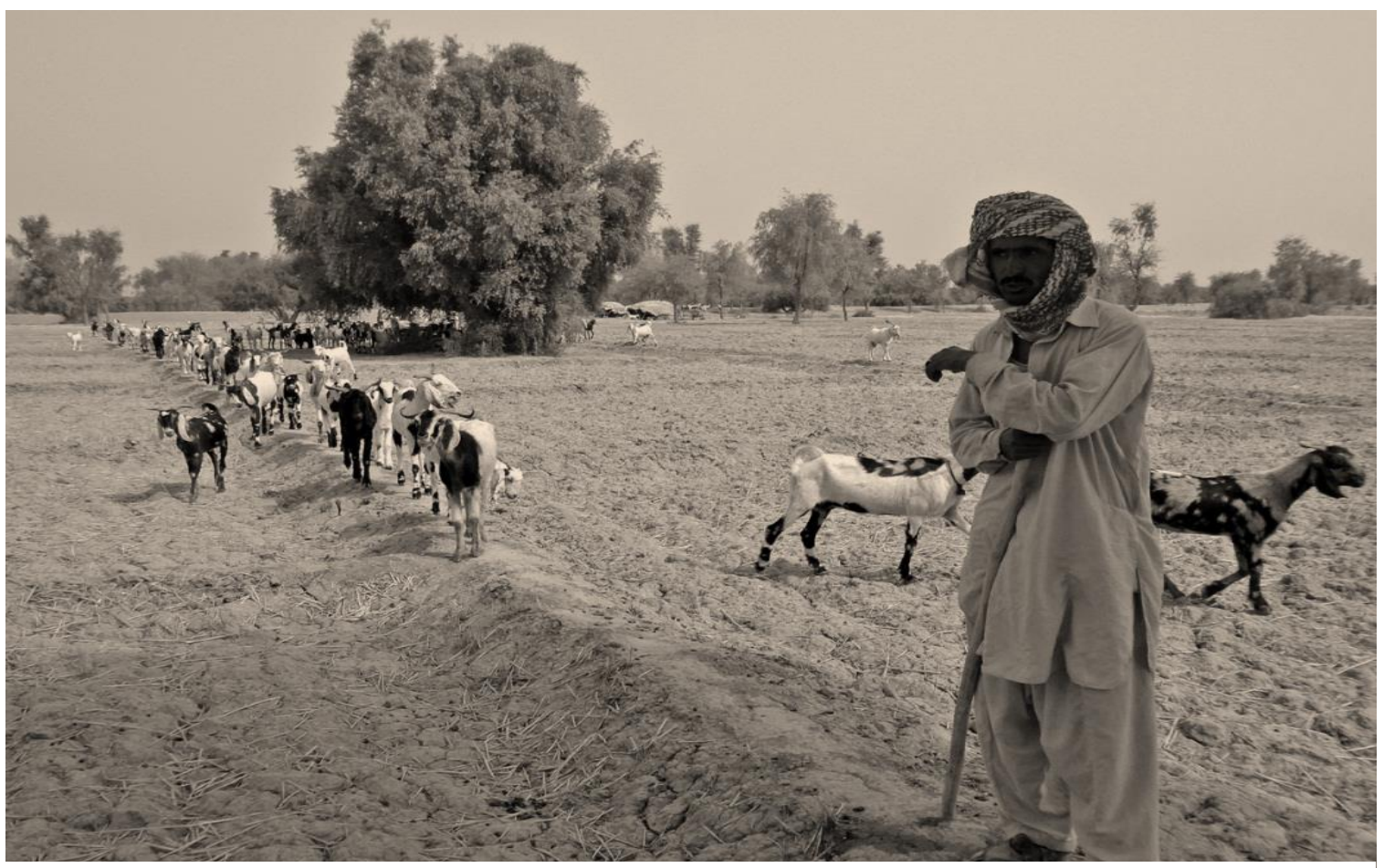

Figure 3: A Baloch (from sub-tribe, Kohira) prepare his herd during mid-day herding

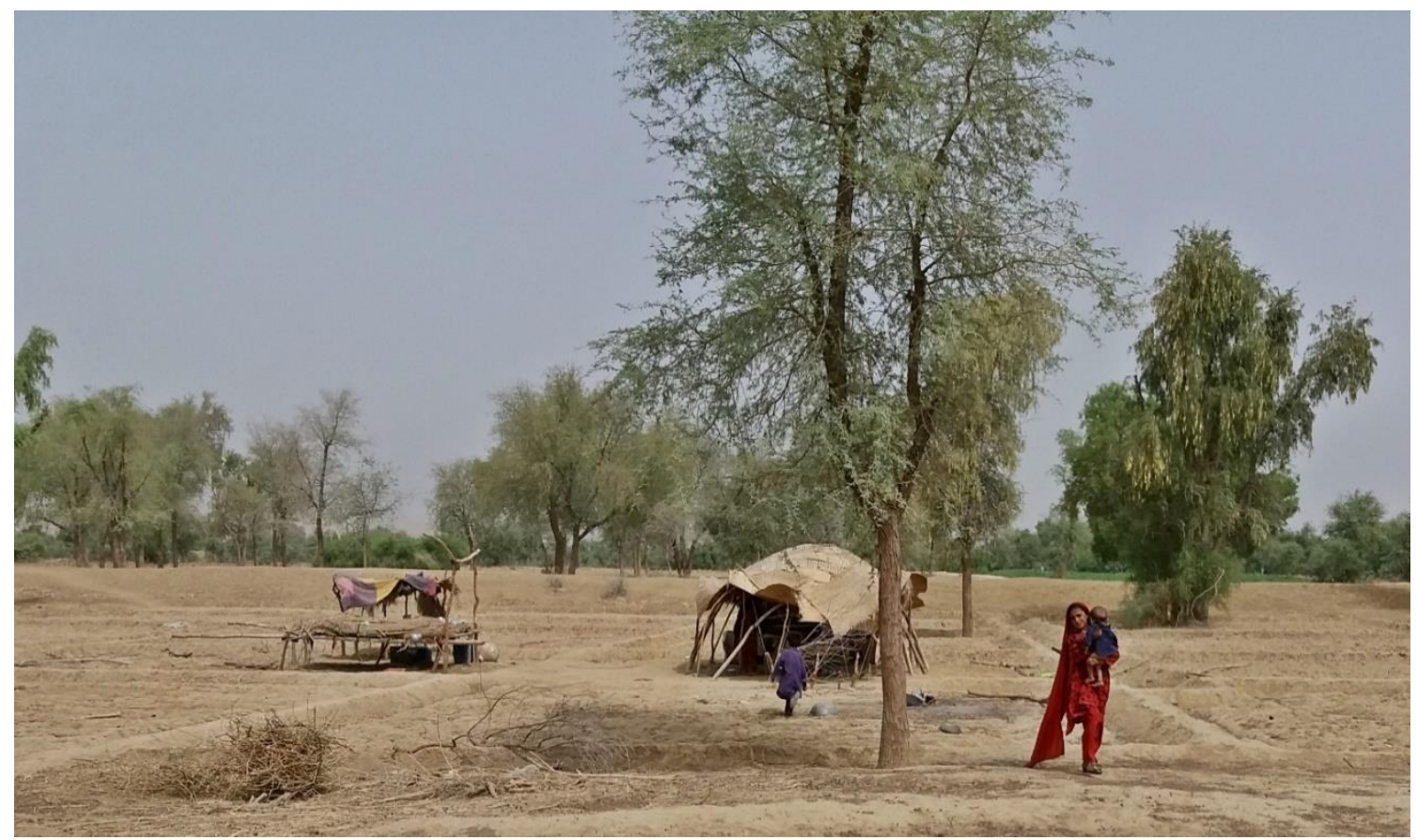

Figure 2: A girl carries her sister to take her at paternal family house. This picture also shows us true nomadic family camp setting. 
Two patterns of movement occur with pastoralism: nomadism and transhumance. Both are based on the fact that herds must move to use pasture available in particular places in different seasons. In pastoral nomadism, the entire group - women, men, and children-moves with the animals throughout the year. With transhumance part of the group moves with the herds, but most people stay in the home village (Kottak, 2011). There are three major types of grazing systems that can be classified in this research which is based on fieldwork; True Nomadic, Transhumant and Sedentary Pastorals ${ }^{4}$. The true nomads follow the seasonal patterns of forage production, spending the summers in the low-temperature highlands of Kirthar and winters in the lowlands of Sindh (Kachho, N.A). A house structure of this pattern of the family is shown in figure 3. Transhumant means that population moves seasonally with herds.

Whereas, sedentary pastorals are most of the people living in the agricultural villages in the area of Wahi Pandhi, which domesticated animals i.e. sheep, goats, and cattle. This type of animal raising also accounts for a major portion of the household income and helps increase farm productivity. Because agriculture production is seasonal and cash crops money comes at end of the season, so livestock is major support for families, especially in illness. Women play a major role, not only in the raising of these animals but also in converting their by-products for daily use and saleable items (Rodriguez, 1994).

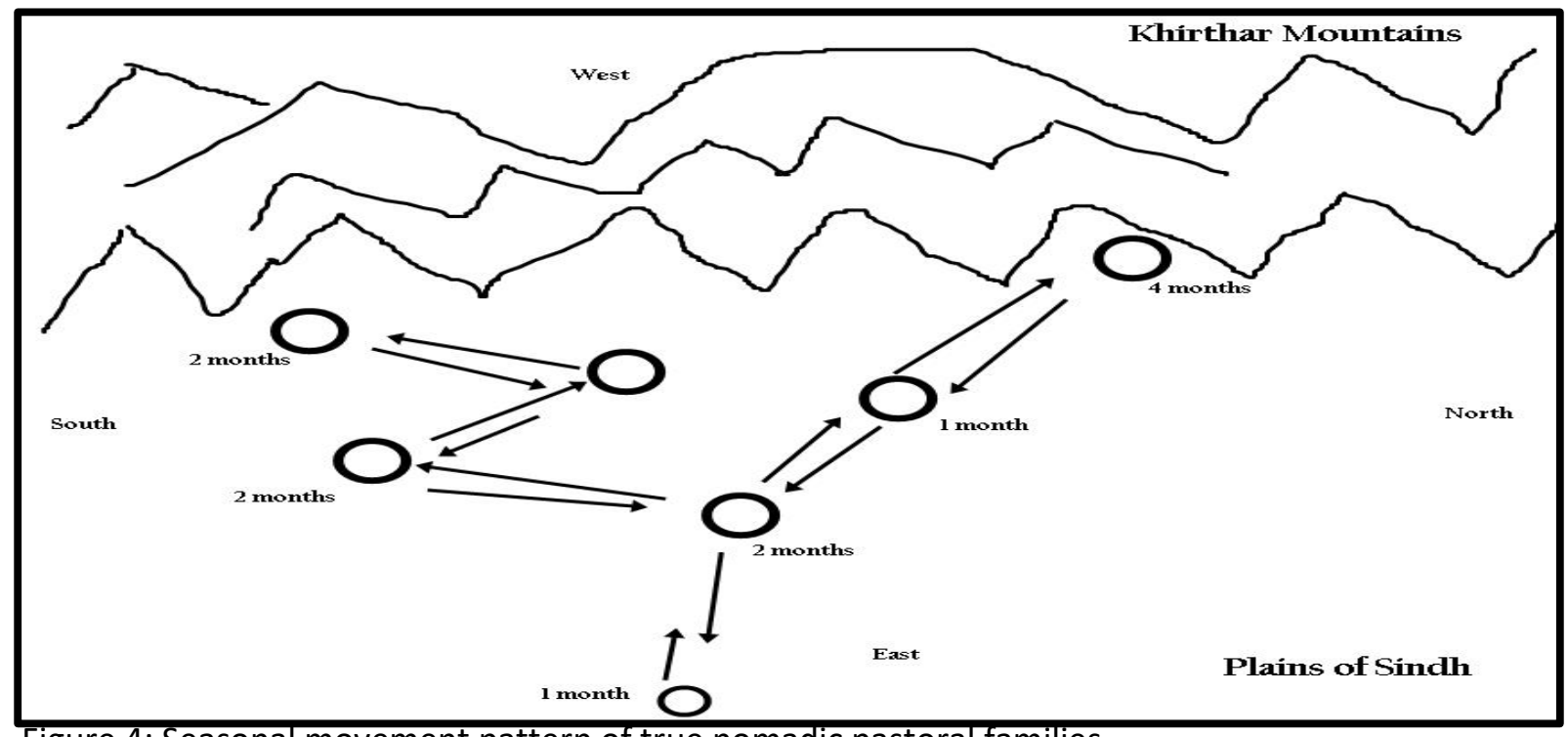

Figure 4: Seasonal movement pattern of true nomadic pastoral families.

\section{Nomadic Migration/Movement Patterns}

Tribes and sub-tribes of Balochs were nomadic mountain tribes. The Balochis were a mountain tribe, who inhabited an extensive tract of wild and barren country from the Hala mountains eastward to the confines of western Persia (Choskey \& Sastry, 2015). History of Balochis written in many books and research articles says that the basic subsistence of Baloch was based on shepherding and pastoralism (Rodriguez, 1994; Rehman, Jasra, \& Fazal, 2001). Same is the case with Wahi Pandhi and surrounding areas. Despite changes in patterns of residence coupled with the introduction of modern technologies in the agriculture sector and integration into a single national market system, Baloch used to spend their lives more as transhumance than sedentary agriculture. They used to change place time by time, once or twice a year depending on resources such as; water, pasture lands, and in search of harvested crops. Migration of sub-tribe and more often than not of clans; that also varies from clan to clan, such as Bozdar tribe. Bozdar tribe still dwells in Gorakh mountainous area and have seasonal movements of winter and summer, where in winter they change the place from the top of Kirthar to

\footnotetext{
${ }^{4}$ Sedentary Pastoral in this paper is used as agro-pastorals, but not entirely as it reflects on a small portion of the population
} 
the bottom plains of Wahi Pandhi, Dadu. However, in summers, they moved towards Gorakh until summers end. Other tribes such as Malokhani, Rind, and Jatt have distinct migration patterns than Bozdars, they change their places in plain, from one district to another also called a circular migration pattern. Choice of place depends on the availability of resources e.g. pastures and fertile lands availability of resources.

\section{Baloch Perception and Trends in Nomadism and Pastoralism Regarding Migration, Changing of Place}

In this part, I will highlight some of the interviews with the respondents, and specifically those answers which are directly related to nomadic migration.

Abid Chutanri: Baloch nomads take their women and kids with them during herding.

Atar Kohira: He has spent his most of life in the mountains, six to seven years ago, they shifted from nomadic life to sedentary agro-pastoral settlement.

Hakim Babar: Mostly nomads do not have jobs, for him it is obvious and he said nomads do not even have CNIC (national identity cards) because pastoral has no permanent place to live and therefore, the government has no policy for them.

Azeem Laghari: I was selling vegetables as vendor in streets of Village Sahib Khan Laghari, then I went to Sakrand Sindh for earning, I spent two to three years (approximately) there, he said but I will tell you that, if you go anywhere in the world for earning "Watan merai, watan en" Now he owns a small shop near his home in Village.

Kehar deen Malukhani: We are famous for $\mathrm{KOH}$ (mountains), we lived there for many years. He further added that their ancestors alsolived in mountains and they came to Wahi Pandhi approximately 10 years ago. Because of quarrels with other Baloch tribes, Sardar forced us to leave the mountain. When after a long fight, we had lost our men, and I lost my one leg, then we decided to migrate to the plains of Indus (Sindh).

Hussain Kohira: Our profession is shepherding, we shifted our life patterns to live permanently in the plains of Wahi Pandhi, and the reason for shifting is long-term drought, so we started farming under supervision of Zamindar, but our shepherding is still existing.

Transformation in Livelihood of Pastoral Communities: Case Studies from World and Pakistan Robert Chambers and Gordon Conway defined livelihood as; "a livelihood comprises the capabilities, assets (stores, resources, claims, and access) and activities required for a means of living". Chambers and Conway were first authors who elaborated the definition of sustainable livelihood. Secondly, agro-pastoralism is a term used to define and conceptualize those people whose livelihood and means of subsistence are combined with both agriculture/cultivation and pastoralism (also discussed as sedentary pastorals). Agriculture is referred as low-scale, seasonal farming ${ }^{6}$. In this context, the research was carried out to measure the qualitative impacts of change among those communities. From the literature, we find that change wasn't rapid but gradual, since the British rule in the subcontinent (India), and also after industrial revolution, developing countries faced drastic changes in economic, politics, culture and society. British rule of over two centuries in India brought farreaching changes in economic systems (Jayapalan, 2012), which in turn had influence on the social structure of society. Although that change was at a macro level, some studies discussed changes at a micro level (globe or world).

For instance, the intervention of intensive markets in small-scale villages boosted the production of agriculture in the region. The large portions of land started to be cultivated and a greater number of people became involved in agricultural production ${ }^{7}$. That extensive agriculture production

\footnotetext{
${ }^{5}$ This translates as; "native country and land has no match, even if you go anywhere in the world"

${ }^{6}$ Landless cultivation. Owns no land and always works as serf/farmer to get some payments at the end of the season and also acquire some grazing land

${ }^{7}$ Anthropological perspective in this regard is; the existence of a market transforms the way indigenous people used their renewable natural resources. Intensification of the market in rural areas changes the choices of people in production and pushes them toward surplus production. Even the shortage of land stimulates livelihoods i.e. pastoralism and nomadism are practiced less as people start to yield according to market demands. (Godoy, García, Byron, Leonard, \& Vadez, 2005)
} 
in long run damaged environment. Environmental changes were named climate change. With the change in climate, rain stopped in some parts of the world, summers became hotter than ever. Snow starts to melt at a high pace and before expected time (not at the usual time). Market intervention is directly related to industrialization. Some impacts of industrialization are found in studies conducted around the world. In a study of Argentina, the author anticipated that impacts of the industrial development process have driven environmental degradation. Other than industrial development, some state policies and interventions also caused a change in livelihood (Tanner, 2003).

The case of Kirthar mountain area has similarities that are noted by De Waroux \& Chiche in a case study of Moroccan society, regarding the change in occupation, their results revealed important changes between 1962 till today, that dominant occupation was farm work and livestock herding that over the period of time changed, and in current time, services, construction, and trade is the dominant occupation (2013). This study has clearly defined the transition, but it did not explain the causative of the market economy on environment and livelihoods.

On another side of literature coming from positivist paradigm and state policy promoters, some scholars articulated subsistence livelihood and pastoral mode of production with higher poverty, for the reason that development approach is established to enhance local village economy for sake of poverty reduction (Reardon \& Vosti, 1995), along with the integration of development, there is an urge to implement positive policies and improve institutional arrangement to enhance socio-economic conditions of pastoralism (Popular \& Rik, 2016).

Chakrabarti reveals in his paper that livelihood in Sikkim mountain area such as pastoralism is deliberately confined by policies and state acts. He was of the view that the state policy emphasized that pastoral grazing activity harm nature and contributes to forest degradation. Writer critique that there is the total absence of the understanding and acknowledgment of the value of nature and of living nature as the environment of human existence. Chakrabarti argues that given these reasons, they must create alternative livelihood avenues, otherwise the old traditional ways will abolish and new livelihood will harm nature and local cultures (Chakrabarti, 2011). Similarly, we can draw from these perspectives that a change in livelihood means a change in the social and economic structures of any society. By this, our societies may not function well as every group and individual has its own specific function to sever. Most of the pastoralists and nomads I interview during field research, I found none educated. Those I interviewed older than 17 years have not enrolled in any school for educational purposes because they have been living in mountains and wandering for pastures of the herd in Sindh or Kirthar and Balochistan. This also hinders the assimilation process of pastoral communities with permanent, rural, and urban communities.

Lack of education limits their access to urban towns and semi-urban areas. Their limited mobility in villages only helps them to get necessities of daily life, basic health, and basic trade. In figure 5 , the head of the nomadic family can be seen. He lived almost entire his life in the mountains. In an interview, he told me that approximately 8-10 years ago, his brother left foraging for herds and settled in Hashim village. Now they are farmers at Zamindar's land. They also herd goats and sheep but they are sedentary, only young males and boys leave for grazing the animals in the morning and return in the evening

\section{TRANSITIONS: CAUSES AND SOLUTIONS}

Since the introduction of the green revolution in the late 1960's, the infrastructure of agricultural production received technological input. The basic technology which green revolution introduced was related to the high yield of crops and a larger number of land cultivation. It helped along the way to make productivity a hundred percent.

In this paper, three apparent causes of a shift are highlighted; first is livelihood, second is market integration and third is environmental change. These theoretical and secondary reasons are very clear, but some of the other reasons which local people have identified and experienced are an obvious threat to pastoral communities in the Kirthar mountain. 
During my field visit, in Kirthar Mountain, my interaction with local nomads gave me an insider perspective. These are reasoning that nomadic pastorals are switching their livelihood to agriculture.

\section{Deteriorating of Forage Resources; Lack of pastures}

Pastures are very important to graze the animal; good pastures play a pivotal role in the nourishment and health condition of herds. Degradation of pastures are due to low rainfall in the region ${ }^{8}$. Secondly, the availability of pastures in the present time depends on the location of the camp, a flock can travel 5-10 kilometers and then come back to camp. Also, it depends on the number of herds in a flock. I interviewed village Soregh, from a pastoral family, who revealed that pastures are rare in June, July, and August. Lack of pastures creates pressure on pastoral communities to move further into areas where they find sufficient pastures to feed herds.

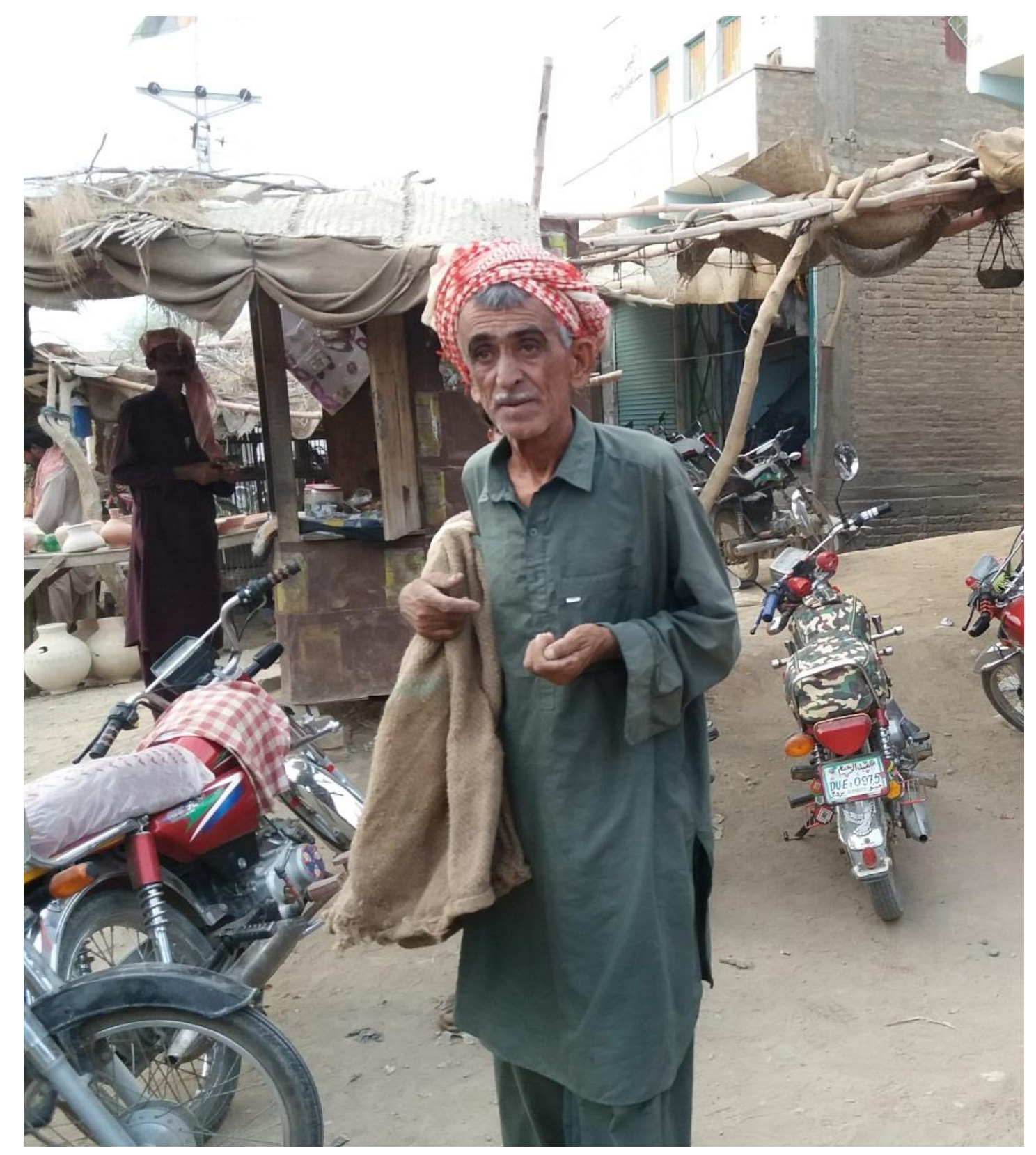

\footnotetext{
${ }^{8}$ This will be further discussed in detail in a very relevant part
} 


\section{Rustamani}

Figure 5: Head of pastoral family, Mohammad Kohira, in middle of Shahr, Wahi Pandhi

Not every area is a common grazing ground, some of the areas are under the control of specific tribes where no other tribesman is allowed to graze their animals.

\section{Water Shortages and Climate Change}

The present study has highlighted that climate change is adversely impacting the pastoral mode of production. Because scorching temperatures during summer in the region make it difficult for pastorals to find a place where they can get the water. In figure 6, we can see a small pond of rainwater. Only rain fills that pond and nearby pastorals come for this water for drinking purpose.

With a change in climate and rainfall per year, pastoralists are facing difficult situations in raising and grazing animals. In an interview with the respondent, I asked them about any relief from a government they have received, all of them answered with no. There is no such policy or drought relief program, even when there are low rains in an area, they must suffer until it rains.

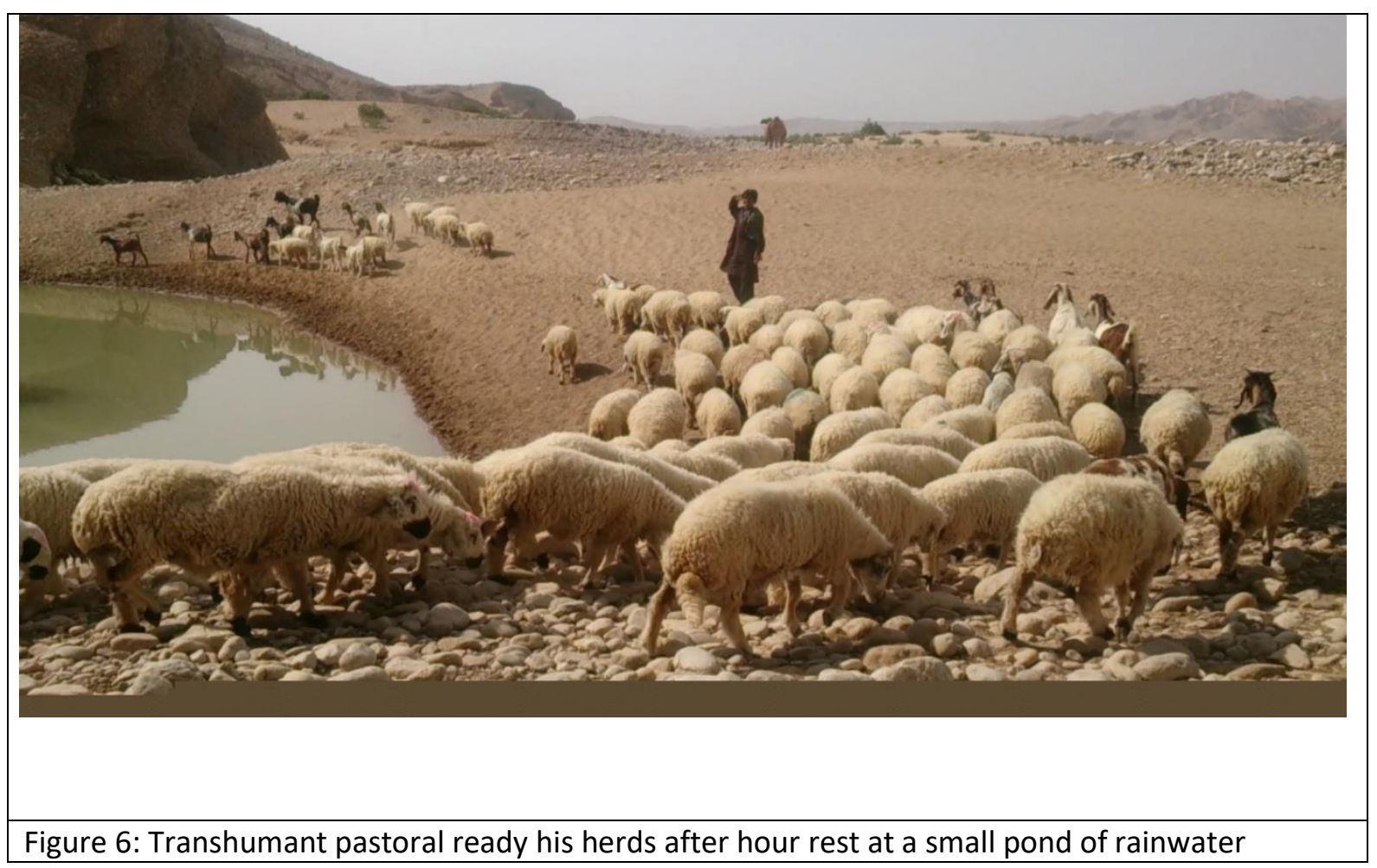

\section{Drought}

In 2000, the area of study (Wahi Pandhi) was under severe drought because of less rainfall in the area. The water table was gone down even in a riverine belt. At that time, the lack of drinking water and vegetation in the area badly affected the livestock, especially the health of animals. According to an assessment report on the drought of 2000 by Relief Web and Pattan Development Organization, local farmers and pastorals started to sell their animals, this also caused the drop in prices of livestock, still, people had to sell their animals in half of the actual price (2000). This made many local shepherds move their animals to far-flung areas, where it was very difficult for them to adjust with the new environment.

\section{Epidemics in Animals}

Livestock contributes 55.91 percent of agriculture value addition. Livestock consist of cattle, buffalos, sheep, goats, camel, horses, asses, mules and poultry and their products. It has registered a growth of 2.88 percent against 3.99 percent last year (Pakistan Economic Survey 2013-14). From these statistics, we find that livestock herding is a major source of income for many families in rural and remote 
areas. Even when it contributes to the economy too, there is less attention being paid to the policies regarding pastoral communities.

When I asked a question about the health of animals, that who bore the expenses of goat or sheep when it gets sick, most of the pastorals answered that we bore all the expenses on their treatment. Even during an outbreak of disease, there is no response from the government to resolve or mitigate the illness. This is also a reason that most pastoralists face higher-level difficulties during the illness of animals. There are no active responses from the government during a difficult situation that pastorals faced.

\section{CONCLUSION}

Market integration of rural village economies have observed dramatic changes in livelihood, whereas the literature shows us that these impacts have somehow degraded the environment, but there is still a need for more meticulous research to understand that what are patterns in which environment is affected in connection to the market. The gap which is found in literature also exists in reality. We as the inhabitants of the world must consider this issue on a priority basis because the environment is our priority.

These days, pastoral livelihood is endangered because of low rains in the area and fewer pastures for a large number of herds. Secondly, common pool resources are being taken by powerful people and by those who live nearby lakes and greenery. In Pakistan and Sindh specifically, there are no strong policies which favor pastoral communities. There is no medical treatment available for livestock and all burden is taken by Pastorals themselves which is also costing a lot of money to them. These Pastorals are switching their livelihood and adopting farming. It gets worse when they switch their livelihood, and with that, they change their lifestyle which they find difficult to adjust with. Some of the Pastoralists, who are now farmers, still live in huts and owns no land, no livestock, and has no identity. This research can be utilized by the scientific community to look into the problems of Pastoral communities which are endangered in Sindh and Balochistan.

\section{REFERENCES}

Barnard, A., \& Spencer, J. (2010). Encyclopedia of Social and Cultural Anthropology (2nd Ed). The Routledge.

Barth, F. (1961). Nomads of South Persia. Little, Brown, and Company.

Chakrabarti, A. (2011). Transhumance, Livelihood and Sustainable Development and Conflict between Formal institution and Communal Governance: An Evaluative Note on East Himalayan State of Sikkim, India. International Conference on Social Science and Humanity, V1-1-V1-7.

Choskey, R.D., \& Sastry, K.S. (2015). The Story of Sindh (An Economic Survey). Indian Council of Historical Research.

De Waroux, Y., \& Chiche, J. (2013). Market Integration, Livelihood Transitions and Environmental Change in Areas of Low Agricultural Productivity: A Case Study from Morocco. Human Ecology, 41(4), 535-545.

Digard, J.P. (1990). L'homme et les animaux domestiques: Anthropologie d'une passion. Fayard.

Godoy, R., García, V.R., Byron, E., Leonard, W.R., \& Vadez, V. (2005). The Effect of Market Economies on the Well-Being of Indigenous Peoples and on Their Use of Renewable Natural Resources. Annual Review of Anthropology 34(1), 121-138.

Jayapalan, N. (2012). Economic History of India - Ancient to Present Day. Atlantic Publishers and Distributers.

Kottak, C.P. (2011). Anthropology Appreciating Human Diversity. McGraw-Hill.

Organisation, P.D. (2000). Pakistan: Drought Assessment Report, District Dadu, Sindh. ReliefWeb.

Popular, G., \& Rik, T. (2016). Transhumant Pastoralism in the Context of Socioeconomic and Climate Change in the Mountains of Nepal. Mountain Research and Development, 36(2), 173-182.

Reardon, T., \& Vosti, S. (1995). Links between rural poverty and the environment in developing countries: Asset categories and investment poverty. World Development, 23(9), 1495-1506.

Rehman, A.U, Jasra, A.W., \& Fazal, M. (2001). Socio-Economics of Pastoralist Communities of Highland Balochistan, Pakistan. International Journal of Agriculture \& Biology, 3(2), 256-259.

Rodriguez, A. (1994). Rangeland Production Systems in Balochistan, Pakistan. Rangelands, 16(1), 21-14.

Rosman, A., Rubel, P.G., \& Weisgrau, M. (2009). The Tapestry of Culture, An Introduction to Cultural Anthropology (9th Edition). Alta Mira Press. 


\section{Rustamani}

Tanner, T. (2003). Peopling Mountain Environments: Changing Andean Livelihoods in North-West Argentina. The Geographical Journal, 169(3), 205-214. 